\title{
Technology of manufacturing the reliable silicon photoconverters with long operation time
}

\author{
N.A. Guseynov ${ }^{1}$, Sh.Q. Askerov ${ }^{1}$, Sh.S. Aslanov², M.N. Agaev ${ }^{1}$, M.H. Gasanov ${ }^{1}$ \\ ${ }^{I}$ Baku State University \\ 23, Z. Khalilov str., Baku, AZ 1148, Azerbaijan, e-mail:nguseynov@mail.ru \\ ${ }^{2}$ Institute of Physics of Azerbaijan National Academy of Sciences \\ 33, G. Djavida prospect, Baku, AZ 1143, Azerbaijan
}

\begin{abstract}
We offer to use an amorphous metal alloy $\mathrm{Al}_{80} \mathrm{Ni}_{20}$ as ohmic contact and current-collecting tracks to silicon photoconverters (PC) based on $p$ - $n$ junctions. Technological processes for production of silicon photosensitive structures and film coatings with an amorphous structure are described. The data of the X-ray structure analysis of the metal alloy $\mathrm{Al}_{80} \mathrm{Ni}_{20}$ confirming amorphism were obtained. The key PC parameters are determined.
\end{abstract}

Keywords: photovoltaic battery, amorphous metal alloy, electron-beam vacuum evaporation.

Manuscript received 09.06.05; accepted for publication 25.10.05.

\section{Introduction}

The priority problem facing the modern power engineering is reduction of the cost to produce the converted solar energy. It can be achieved by technological development of their manufacturing, use of cheaper and new materials, increase reliability of growth and operating time of photoconverters (PC) [1].

To provide reliable growth of $\mathrm{PC}$, it is necessary to find the cause resulting in the degradation and to use various methods for prevention of this degradation.

\section{Substantiation of using the material}

The reasons of wide application of $\mathrm{Al}$ as ohmic contacts in microelectronics are as follows: the small values of resistance $R_{\kappa}$ of the contacts $\mathrm{Al} / p-\mathrm{Si}$, a good heat conductivity, a low cost of the material.

However, the application of the polycrystalline $\mathrm{Al}$ in solar power engineering has several failings. First, Al is not convenient metal for the assembly of $\mathrm{PC}$ in a solar battery, because it is possible to make the contact to $\mathrm{Al}$ only by welding or thermocompression. In this connection, it is necessary to deposit other metals, for example $\mathrm{Ag}$, over $\mathrm{Al}$ contact. Second, the resistance $R_{K}$ of contacts $\mathrm{Al} / p$-Si increases with increasing the temperature, hence, when operating at higher illumination levels such ohmic contact is not suitable [2].

There is one more cause of untilizing the polycrystalline $\mathrm{Al}$ as an ohmic contact.
As known, one of the cause of semiconductor device degradation is migration of atoms from ohmic contact material to the semiconductor $[2,3]$.

In polycrystalline metal, transport ways for migrating atoms are grain boundaries and various defects (dislocations, vacancies, etc.). To prevent atomic migration, perspective is the use of relaxed amorphous metal alloys in which there are neither grain boundaries, nor dislocations that are inherent to the crystalline state. In this case, the structure is homogeneous and, as a consequence, the diffusion is strongly slowed down [4].

In this work, investigated is the opportunity of application of the metal film $\mathrm{Al}_{80} \mathrm{Ni}_{20}$ with amorphous structure as ohmic contacts and current-collecting tracks when manufacturing the solar batteries [5]. Characteristic feature of this film production is a comparative technological simplicity of tinning in assembly processes, which plays an important role as it excludes the use of such expensive metals as gold, silver, etc.

The finished PC structure is shown in Fig. 1.

\section{Technology for production of photoconverters}

To obtain the shallow diffusion $n^{+}$and $p^{+}$areas, the industrial plant DOM-3 was used.

The temperature of an operating reactor zone was $950{ }^{\circ} \mathrm{C} ; \mathrm{N}_{2}, \mathrm{O}_{2}$ were used as technological gases. $\mathrm{PCl}_{3}$ was a source of phosphorus. The $280-\mu \mathrm{m}$ thick plates of monocrystalline silicon SHB-10 (111) were applied as substrates. The value of substrate specific resistance 


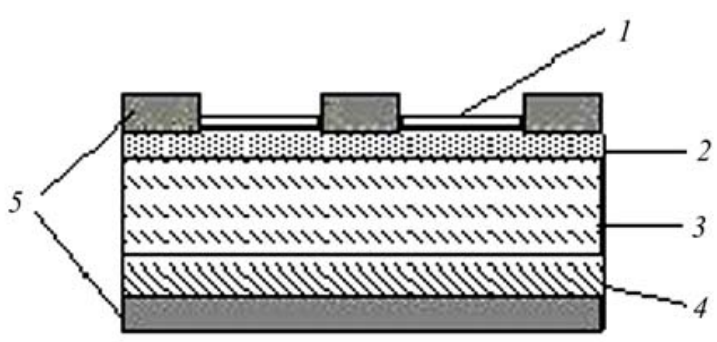

Fig. 1. Photoconverter structure.

1 - the antireflection coating - phosphorsilicate glass; 2 $n^{+}$-Si:(P) $\quad\left(N_{\mathrm{D}}=1 \cdot 10^{20} \mathrm{~cm}^{3}\right) ; 3-p$-Si SHB10 (111) $\left(N_{\mathrm{A}}=1 \cdot 10^{16} \mathrm{~cm}^{3}\right) ; 4-p^{+}$-Si:(B) $\left(N_{\mathrm{A}}=1 \cdot 10^{17} \mathrm{~cm}^{3}\right) ; 5$ - the ohmic contact made from the amorphous metal alloy $\mathrm{Al}_{80} \mathrm{Ni}_{20}$.

averaged $9 \Omega \cdot \mathrm{cm}$ that corresponded to the value of the impurity concentration of $1 \cdot 10^{16} \mathrm{~cm}^{3}$. The process for producing the $\mathrm{PC}$ before the ohmic contact coating was presented by the following basic technological operations.

1. Chemical treatment (peroxide of ammoniac solutions).

2. Oxidation $\left(T=1050{ }^{\circ} \mathrm{C}, \mathrm{O}_{2}, \mathrm{~N}_{2}, \mathrm{H}_{2} \mathrm{O}+\mathrm{Cl}\right)$.

3. $\mathrm{SiO}_{2}$ disposal from the backside $\left(\mathrm{H}_{2} \mathrm{O}: \mathrm{HF}\right)$.

4. Chemical treatment (peroxide of ammoniac solutions).

5. Boron diffusion $\left(\mathrm{BBr}_{3}\right)$.

6. $\mathrm{SiO}_{2}$ disposal from the front side $\left(\mathrm{H}_{2} \mathrm{O}: \mathrm{HF}\right)$.

7. Chemical treatment (peroxide of ammoniac solutions).

8. Phosphorus diffusion $\left(\mathrm{PCl}_{3}\right)$.

Before ohmic metallization, the photosensitive structures were separated into three groups. Then, the polycrystalline Al film was evaporated onto the structures of the first group, the film of polycrystalline $\mathrm{Ni}$ - onto those of the second one, and the amorphous metal alloy $\mathrm{Al}_{80} \mathrm{Ni}_{20}$ film - onto those of the third one.

Process of metallization of structures has several consecutive operations:

1. Photolithography (opening the windows on the front side).

2. Chemical treatment (peroxide of ammoniac solutions).

3. Metal film evaporation onto the front side.

4. Photolithography on the metal.

5. Metal film evaporation onto the backside.

Finally, on the front side of structure we obtained the pattern with the identical step, and on the backside - the continuous layer of the metal contact.

Using the made structures, we have determined:

- type of the diffusion layer conductivity;

- thickness of $n^{+}$area $d_{n}$;

- specific surface resistivity of substrates $R_{s s}$ and diffusion layers $R_{\text {sdl }}$;

- specific bulk resistivity of substrates $\rho_{v s}$ and diffusion layers $\rho_{v d l}$;
- impurity concentration $N$;

- short-circuit current $I_{s c}$ and open-circuit voltage $U_{\mathrm{op}}$.

The value $d_{p-n}$ was determined by the method spherical joint in several "points" of the structure at the interface using a microscope.

$R_{s s}$ and $R_{s d l}$ was measured using the 4-probe method [5].

The values $\rho_{v s}$ and $\rho_{v d l}$ were calculated by the formula:

$\rho_{v d l}=R_{s} d$,

where $d$ is the thickness of a substrate or diffusion layer.

The value $N$ was determined from the experimentally measured dependences of specific resistance on the impurity concentration in $n$-type silicon doped by phosphorus [6].

The values $I_{s c}$ and $U_{\text {op }}$ were determined from the load voltage-current characteristics.

The obtained results are shown in Table 1.

Table 1.

\begin{tabular}{|l|c|c|c|c|c|c|}
\hline $\begin{array}{c}\text { Parameter } \\
\text { Structure }\end{array}$ & $\begin{array}{c}I_{s c}, \\
\mathrm{~mA}\end{array}$ & $\begin{array}{c}U_{\mathrm{op}}, \\
\mathrm{V}\end{array}$ & $\begin{array}{c}R_{s p+}, \\
\Omega \cdot \mathrm{cm}\end{array}$ & $\begin{array}{c}R_{s n+}, \\
\Omega \cdot \mathrm{cm}\end{array}$ & $\begin{array}{c}\rho_{v p+}, \\
\mu \Omega\end{array}$ & $\begin{array}{c}\rho_{v n^{+}}, \\
\mu \Omega\end{array}$ \\
\hline I group (Al) & 22 & 5.2 & 140 & 40 & 700 & 12 \\
\hline $\begin{array}{l}\text { II group } \\
\text { (Ni) }\end{array}$ & 19.5 & 4.9 & 140 & 40 & 700 & 12 \\
\hline $\begin{array}{l}\text { III group } \\
\left(\mathrm{Al}_{80} \mathrm{Ni}_{20)}\right.\end{array}$ & 21 & 5.1 & 140 & 40 & 700 & 12 \\
\hline
\end{tabular}

\section{Method for producing the amorphous metal films}

The industrial plant "ORATORIO-9" was used for evaporation of the amorphous alloy Al-Ni films by the vacuum electron-beam evaporation method. The conditions of evaporation were chosen in such manner that the film structure was corresponded to the alloy $\mathrm{Al}_{80} \mathrm{Ni}_{20}$.

Conditions for obtaining the necessary concentration ratio are summarized in Table 2 .

Table 2.

\begin{tabular}{|l|l|}
\hline Operating vacuum & $P=5 \cdot 10^{-5} \mathrm{~mm} \mathrm{Hg}$ \\
\hline Substrate temperature & $T=250^{\circ} \mathrm{C}$ \\
\hline Evaporation current of $\mathrm{Al}$ & $I_{\mathrm{Al}}=12 \mu \mathrm{A}$ \\
\hline Evaporation current of $\mathrm{Ni}$ & $I_{\mathrm{Ni}}=2.2 \mu \mathrm{A}$ \\
\hline Evaporation time & $t=300 \mathrm{~s}$ \\
\hline Film thickness & $d_{\mathrm{AlNi}}=0.5 \mu \mathrm{m}$ \\
\hline
\end{tabular}

\section{The structural analysis of $\mathrm{Al}, \mathrm{Ti}, \mathrm{Al}_{80} \mathrm{Ni}_{20}$ films}

To identify the structure of metal films after evaporation, the X-ray structural analysis has been carried out using the diffractometer DRON-2.

In Fig. 2 shown are the X-ray diffraction rocking curves obtained for the pure polycrystalline $\mathrm{Al}, \mathrm{Ni}$, and $\mathrm{Al}_{80} \mathrm{Ni}_{20}$ films. A primary beam $(\lambda=1.54 \AA)$ was 


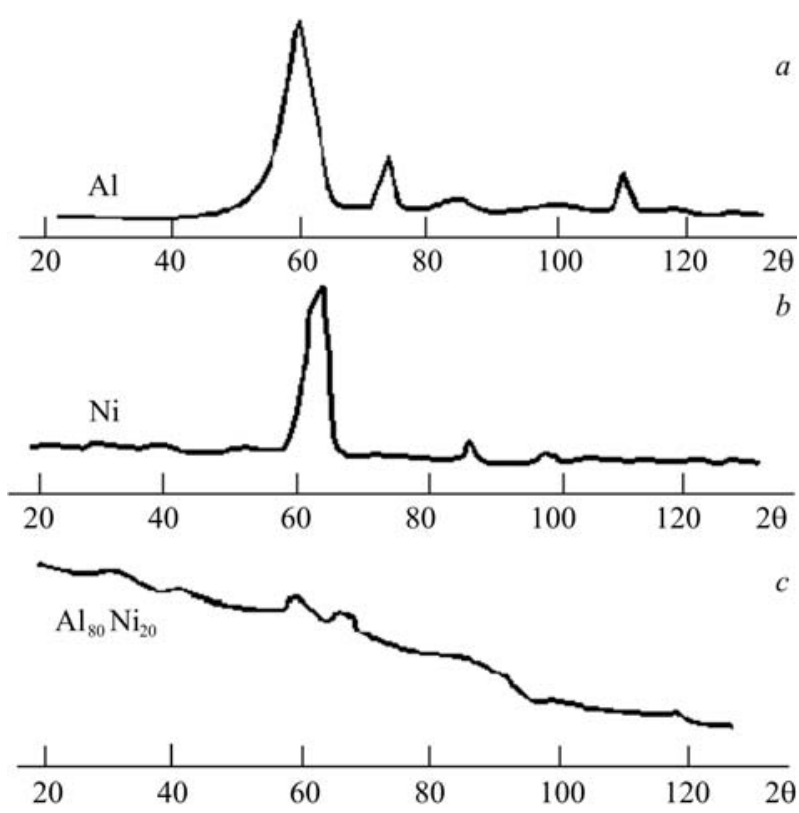

Fig. 2. X-ray structure analysis films $\mathrm{Al}$ (a), $\mathrm{Ni}(\mathrm{b})$ и $\mathrm{Al}_{80} \mathrm{Ni}_{20}$ (c).

monochromated by a pyrolitic graphite crystal. As may be seen from the X-ray photographs for aluminium and nickel films, the interference maximuma observed (Figs $2 \mathrm{a}$ and $\mathrm{b}$ ) are characteristic for the polycrystalline films of pure metals.

In the case of $\mathrm{Al}_{80} \mathrm{Ni}_{20}$, diffraction peaks are strongly smoothed, that is evident of film amorphism (Fig. 2c).

For confirmation of this conclusion, the electronmicroscopical analysis have been carried out [7].

\section{Results}

The silicon PC based on p-n junction with $\mathrm{Al}_{80} \mathrm{Ni}_{20}$ ohmic contact made in 1987 reduces its efficiency less than by $10 \%$ after 17 years of service, the one with polycrystalline metal ohmic contact reducing the efficiency more than by $20 \%$. This fact testifies reliability and long operation time of solar batteries proposed by us.

\section{Conclusions}

Thus, we can conclude that the use of $\mathrm{Al}_{80} \mathrm{Ni}_{20}$ ohmic contacts, first, raises the stability and reliability, second, increases the service life of solar batteries, and, thirdly, lowers the cost of converted solar energy production.

\section{References}

1. V.L. Avgustinov, T.N. Belousova, Modern status of energy photoconversion by using silicon solar elements // Optoelectronics and Semiconductor Technics, 30, p. 120-154 (1995) (in Russian).

2. V.I. Striha, S.S. Kilchinskaya, Solar elements based on contact the metal - semiconductor, Kyiv, Naukova dumka (1992) (in Russian).

3. V.R. Zayavlin, Temperature degradation of the solar photovoltaic array // Solar Eng., N5, p. 3-17(1999).

4. I.V. Zolotukhin, Y.E. Kalinin, Amorphous metallic alloys // Uspekhi Fiz. Nauk, 160, N9, p.75-100 (1990) (in Russian).

5. Sh.Q. Askerov, M.N. Agaev, M.H. Hasanov, V.A. Orujov, N.A. Guseynov, Solar cell on the basis of $p$ - $n$ junction from $p$-Si with metallization from amorphous metallic alloy $\mathrm{Al}_{80} \mathrm{Ni}_{20}$ // Transactions of Azerbaijan National Academy of Sciences, XXIII, N5(II), p.66-69 (2003).

6. L.P. Pavlov, Methods of determination of key parameters of semiconduction materials, Visshaya shkola, Moscow (1975) (in Russian).

7. I.G. Pashaev, Ph.D. thesis (1990). 